\title{
Seizures as an Atypical Feature of Beal's Syndrome
}

"Nazreen B. K. Jaman and Abeer Al-Sayegh

$$
\text { نوبات التشنج سمة غير شائعة في متلازمة بيلز }
$$

$$
\text { نازرين بانو كمارس جمان و عبير الصائغ }
$$

\begin{abstract}
Congenital contractural arachnodactyly, commonly known as Beal's syndrome, is an extremely rare genetic disorder caused by mutations in the fibrillin-2 (FBN2) gene located on chromosome 5q23. It is an autosomal dominant inherited connective tissue disorder characterised by a Marfan-like body habitus, contractures, abnormally shaped ears and kyphoscoliosis. We report a seven-year-old Omani male who presented to the Sultan Qaboos University Hospital, Muscat, Oman, in 2014 with seizures. He was noted to have certain distinctive facial features and musculoskeletal manifestations; he was subsequently diagnosed with Beal's syndrome. Sequencing of the FBN2 gene revealed that the patient had a novel mutation which was also present in his mother; however, she had only a few facial features indicative of Beal's syndrome and no systemic involvement apart from a history of childhood seizures. To the best of the authors' knowledge, this is the first report of Beal's syndrome with seizure symptoms as a potential feature.
\end{abstract}

Keywords: Congenital Contractural Arachnodactyly; Marfan Syndrome; Fibrillin-2; Seizures; Case Report; Oman.

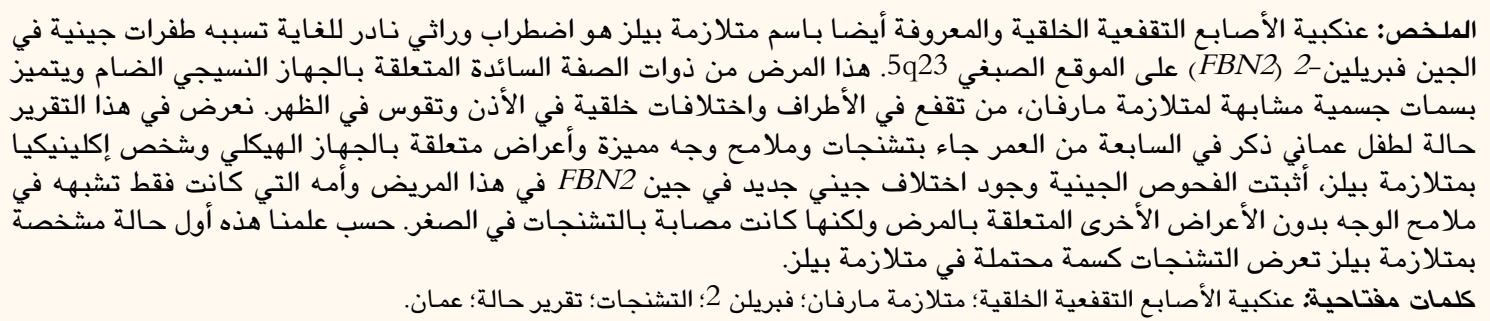

$\mathrm{B}$ EAL'S SYNDROME (ONLINE MENDELIAN Inheritance in $\operatorname{Man}^{\circledR}$ entry \#121050), also known as congenital contractural arachnodactyly, is an autosomal dominantly inherited connective tissue disorder characterised by multiple flexion contractures, arachnodactyly, severe kyphoscoliosis, abnormal pinnae and muscular hypoplasia. ${ }^{1,2}$ The syndrome was first described in 1971 by Beal et $a l .^{3}$ This report describes a case of Beal's syndrome with seizures as a potential feature. To the best of the authors' knowledge, seizures have not previously been reported as a characteristic of Beal's syndrome. This case also highlights the importance of genetic screening for family members of patients with Beal's syndrome.

\section{Case Report}

A seven-year-old Omani male was admitted to the Sultan Qaboos University Hospital, Muscat, Oman, in 2014 with seizures. He had been born at fullterm gestation by Caesarean section due to nonprogression of the second stage of labour. At birth, he had a good Apgar score and his growth parameters were normal. There were no antenatal or perinatal concerns and no significant maternal illness or history of drug intake. However, as a newborn, contractures in both lower limbs were observed; these were treated by orthopaedic specialists with plaster of Paris cast applications. The patient's developmental progress was appropriate for his age. He displayed delayed gross motor development and stood up late; however, his parents showed no concern and he began walking without support at 18 months. A hearing test was normal and a vision test showed a refractive error, for which he was prescribed glasses. The patient was in grade 1 at school and had no learning difficulties, although he experienced minor difficulties in holding his pen due to finger contractures. His mother reported that he had been bullied at school because 

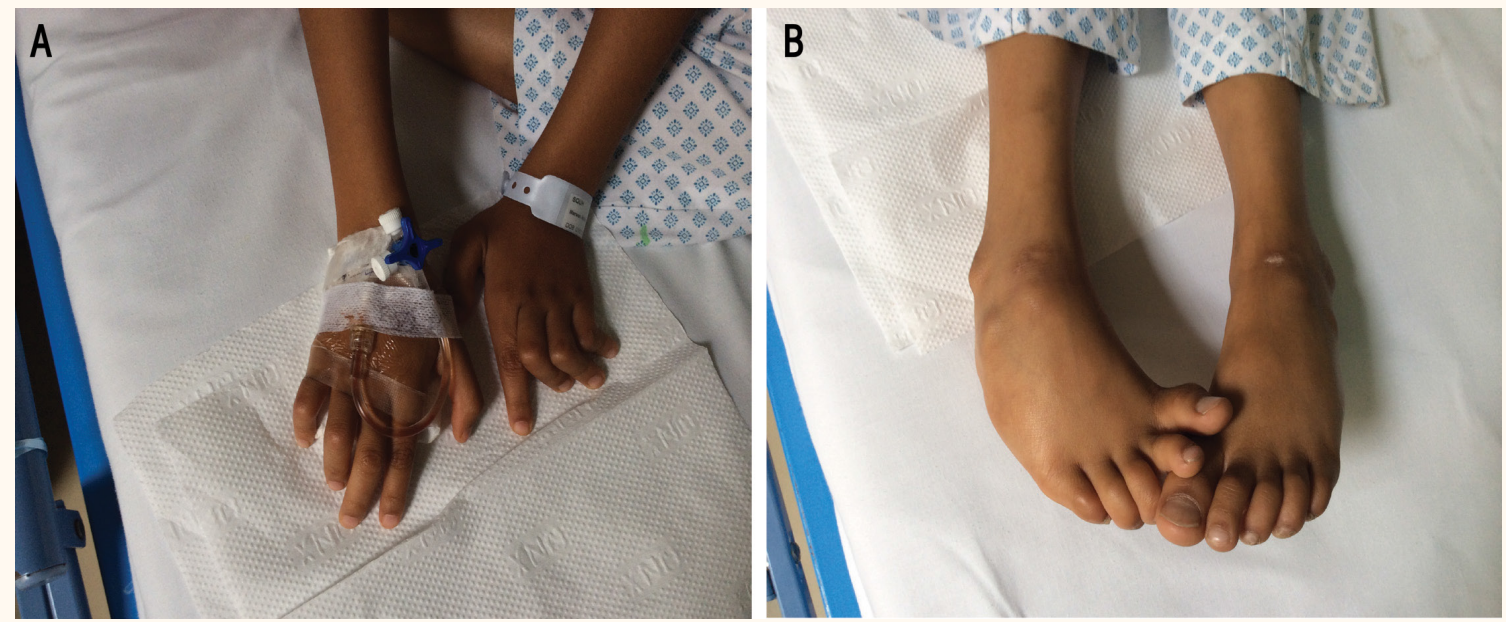

Figure 1A \& B: Photographs demonstrating (A) upper limb camptodactyly and (B) lower limb contractures in a patient with Beal's syndrome.

of his physical appearance. For this reason, the patient had undergone counselling, which both the patient and his parents reported to be helpful.

At admission, the patient was referred to the Clinical Genetics team as he was noted to have certain features suggestive of Beal's syndrome. A clinical examination revealed that he had a broad forehead, arched eyebrows, a broad and flat nasal bridge, facial asymmetry with a small mouth, retrognathia, a high arched palate, low posterior hairline and a short neck. His ears were low set, fanning laterally. Camptodactyly was noted in both hands as well as contractures in both feet [Figure 1]. The patient was observed to have both pectus carinatum with a small excavation in the mid sternum along with a café au lait spot of more than $1 \mathrm{~cm}$ on the right leg. He had big prominent eyes with ptosis, which was mainly present in the left eye. With regards to growth parameters, the patient was below the $25^{\text {th }}$ percentile for height and below the $10^{\text {th }}$ percentile for weight. His head circumference was smaller than average (below the mean 50\%). He scored
70 on an intelligence quotient test, which was classified as borderline deficiency. Computed tomography of the brain was normal; however, an electroencephalogram showed right occipital lobe spikes and spike wave discharges suggestive of partial seizures. A skeletal survey indicated that the bones and joints of the lower extremities had a normal appearance. An ophthalmology examination showed hypermetropia in both eyes and an echocardiogram showed aortic root dilatation.

In view of his physical features, the patient was diagnosed with Beal's syndrome. With regards to family pedigree, he was the eldest son of consanguineous first cousin parents [Figure 2]. He had a healthy younger sister who did not share his physical characteristics. While he resembled both parents, his mother also had a small mouth, small chin and high arched palate. She reported that she had a history of childhood epilepsy, which improved with age; she was currently not on any anti-epileptic drugs at the time. In addition, she also revealed that most of the members of her family-

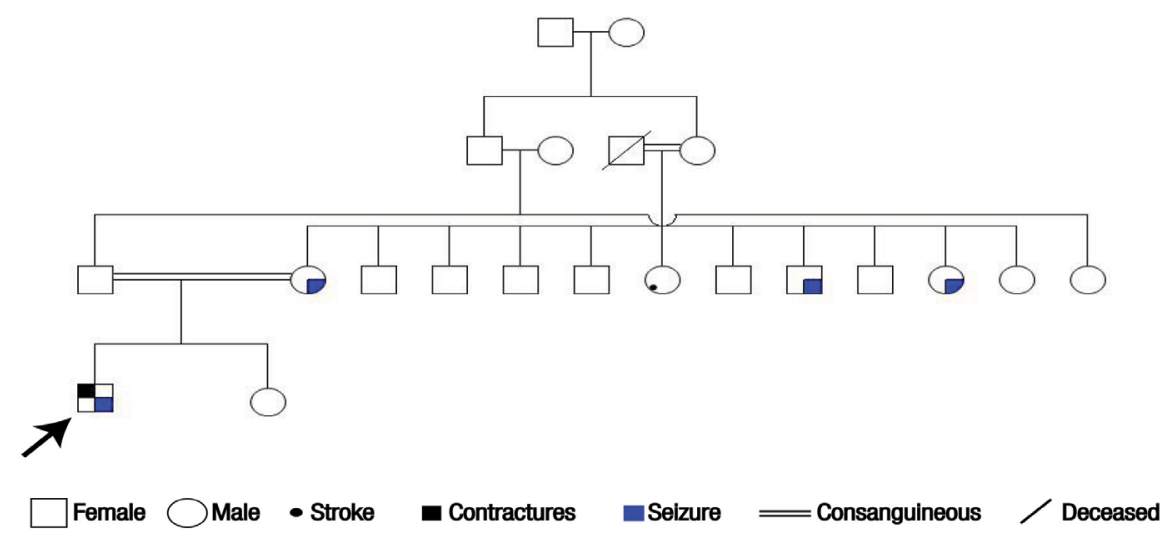

Figure 2: Family pedigree chart of a patient with Beal's syndrome (arrow). 
including her parents, siblings and cousins as well as cousins on her husband's side of the family - shared the same facial features but had no systemic involvement indicative of Beal's syndrome, other than a history of childhood epilepsy in the patient's maternal uncle and aunt. The latter family member had also suffered a stroke at a young age.

Molecular sequencing of the fibrillin-2 (FBN2) gene showed that the patient had a new mutation in exon 46, c.5847A>G (p.Lys1949Lys). Five splice site prediction programs were used in the testing process. Of these, the Alamut ${ }^{\circledR}$ Visual (Interactive Biosoftware, Rouen, France), Sorting Intolerant from Tolerant, Align-GVGD (Huntsman Cancer Institute, Salt Lake City, Utah, USA) and Multivariate Analysis of Protein Polymorphism programs suggested that the c.5847A $>\mathrm{G}$ variant would activate a cryptic guaninethymine donor site upstream. ${ }^{4,5}$ Subsequent genetic testing of the patient's parents showed that his mother was a carrier of the same FBN2 mutation. Despite this, she had only a few facial features indicative of Beal's syndrome and no systemic involvement apart from the history of seizures. Molecular genetic testing of the patient's father did not show any mutation of the $F B N 2$ gene.

\section{Discussion}

A diagnosis of Beal's syndrome is mainly based on clinical findings. ${ }^{6}$ Marfan's syndrome and homocystinuria can be considered in the differential diagnosis for Beal's syndrome. Patients with Beal's syndrome may display similar skeletal features to those with Marfan's syndrome, such as marfanoid habitus, arachnodactyly, camptodactyly and kyphoscoliosis. ${ }^{2}$ However, the ear helix of patients with Beal's syndrome often has a crumpled appearance; in addition, patients have congenital contractures and do not typically have the same ocular and cardiovascular complications seen in Marfan's syndrome. ${ }^{2}$ Although the presence of contractures is specific to Beal's syndrome, there have been reports of patients with Marfan's syndrome with mild contractures. ${ }^{2}$ Patients with Marfan's syndrome have lens subluxation, which is not a typical feature of Beal's syndrome. ${ }^{6}$ Moreover, it is estimated that general ocular complications are only present in $20 \%$ of Beal's syndrome patients. ${ }^{2}$ Aortic root dilatation and mitral valve prolapse are the most common cardiovascular complications in Marfan's syndrome, whereas cardiac findings in Beal's syndrome include aortic enlargement and/or mitral valve regurgitation. ${ }^{2}$

Clinical features overlap between Beal's syndrome and Marfan's syndrome because each of these conditions result from mutations in two highly similar but distinct homologous genes, FBN2 and FBN1, respectively, situated in chromosomes 5 q23-31 and 15q15-21.3, respectively. The FBN2 gene is located on chromosome $5 \mathrm{q} 23$ and is responsible for encoding the extracellular matrix microfibril fibrillin- $2 .^{6}$ Previous research has found that over 20 mutations in the FBN2 gene can cause Beal's syndrome; these mutations can change the amino acid structure of the fibrillin-2 protein-such as the replacement of cysteine with a different amino acid-which may lead to either structural or functional changes in the protein. ${ }^{8}$ In the present case, the patient was admitted with seizures and subsequently diagnosed with Beal's syndrome. There is the possibility that the seizures may be an unrelated finding; to the best of the authors' knowledge, seizures are not a typical finding in reported cases of Beal's syndrome in the literature.

The management of Beal's syndrome is largely symptomatic. The joint contractures may resolve with time, with residual camptodactyly persisting. ${ }^{2,6}$ However, spine curvature problems may be seen at birth or during early childhood. ${ }^{6}$ An early diagnosis and multidisciplinary management with physiotherapy and occupational therapy can help to prevent the progression of these orthopaedic issues, enabling patients to carry on with their day-to-day activities with ease. Routine physical examinations for spinal deformities and early intervention for scoliosis can prevent morbidity later in life. ${ }^{6}$ An initial cardiac evaluation with serial echocardiography is recommended, as cardiac complications may arise. ${ }^{6}$ A thorough ophthalmological evaluation is also recommended to rule out any ocular involvement. Individuals with Beal's syndrome are usually able to live normal lives unless they suffer from cardiac problems or severe deformities of the vertebrae.

Many patients with Beal's syndrome also have an affected parent, although occasionally Beal's syndrome can be caused by a de novo gene mutation. ${ }^{6}$ The risk to the patient's siblings can be estimated after assessing the genetic status of the parents. If one of the parents is found to have clinical features, then there is a $50 \%$ chance that their children will also have Beal's syndrome due to its pattern of autosomal dominant inheritance. ${ }^{6}$ There have been reported cases of Beal's syndrome associated with germline mosaicism. If a Beal's syndrome-causing mutation is found in one member of the family, prenatal testing can be offered to other family members. ${ }^{6}$

\section{Conclusion}

This is the first reported case of Beal's syndrome with a feature of seizures, although there is a possibility 
that the seizures were an unrelated finding. Molecular sequencing of the patient's FBN2 gene showed a new mutation in exon 46, c.5847A $>$ G (p.Lys1949Lys). While his mother carried the same variant, she shared only a few facial features and none of the classic features of Beal's syndrome. This report indicates the importance of early genetic screening of other family members to assess the risk of recurrence.

\section{References}

1. Online Mendelian Inheritance in Man. Entry \#121050: Arthrogryposis, distal, type 9. From: www.omim.org/entry/ 121050 Accessed: Jan 2016.

2. Tunçbilek E, Alanay Y. Congenital contractural arachnodactyly (Beals syndrome). Orphanet J Rare Dis 2006; 1:20. doi: 10.11 86/1750-1172-1-20.

3. Beals RK, Hecht F. Congenital contractural arachnodactyly: A heritable disorder of connective tissue. J Bone Joint Surg Am 1971; 53:987-93.
4. J. Craig Venter Institute. Sorting Intolerant from Tolerant (SIFT). From: sift.jcvi.org/ Accessed: Jan 2016

5. Stone EA, Sidow A. Physicochemical constraint violation by missense substitution mediates impairment of protein function and disease severity. Genome Res 2005; 15:978-86. doi: 10.1101/ gr.3804205.

6. Godfrey M. Congenital contractural arachnodactyly. In: Pagon RA, Adam MP, Ardinger HH, Wallace SE, Amemiya A, Bean LJ, et al., Eds. GeneReviews ${ }^{\circledR}$. Seattle, Washington, USA: University of Washington, 2016.

7. Callewaert BL, Loeys BL, Ficcadenti A, Vermeer S, Landgren M, Kroes HY, et al. Comprehensive clinical and molecular assessment of 32 probands with congenital contractural arachnodactyly: Report of 14 novel mutations and review of the literature. Hum Mutat 2009; 30:334-41. doi: 10.1002/ humu.20854.

8. Ramos Arroyo MA, Weaver DD, Beals RK. Congenital contractural arachnodactyly: Report of four additional families and review of literature. Clin Genet 1985; 27:570-81. doi: 10.1111/j.1399-0004.1985.tb02042.x. 